\title{
Letter \\ Use of methotrexate therapy is not associated with decreased prevalence of metabolic syndrome - authors' response
}

\author{
Tracey E Toms ${ }^{1,2}$, Vasileios F Panoulas ${ }^{1}$, Holly John ${ }^{1}$, Karen MJ Douglas ${ }^{1}$ and George D Kitas ${ }^{1,2}$
}

\begin{abstract}
1Department of Rheumatology, Dudley Group of Hospitals NHS Trust, Russells Hall Hospital, Pensnett Road, Dudley, West Midlands, DY1 2HQ, UK ${ }^{2}$ ARC Epidemiology Unit, Manchester University, Oxford Road, Manchester, M13 9PT, UK
\end{abstract}

Corresponding author: George D Kitas, gd.kitas@dgoh.nhs.uk

Published: 21 September 2009

Arthritis Research \& Therapy 2009, 11:414 (doi:10.1186/ar2806)

This article is online at http://arthritis-research.com/content/11/5/414

(c) 2009 BioMed Central Ltd

See related research by Toms et al., http://arthritis-research.com/content/11/4/R110, and related letter by Raterman et al., http://arthritis-research.com/content/11/5/413

We thank Raterman and colleagues for their interest in our article 'Methotrexate therapy associates with a reduced prevalence of the metabolic syndrome in rheumatoid arthritis patients over the age of 60: more than just an anti-inflammatory effect? A cross-sectional study' [1]. Raterman and colleagues replicated our analyses in their cohort of 353 rheumatoid arthritis (RA) patients from Holland but were unable to demonstrate or confirm an association between methotrexate (MTX) use and the metabolic syndrome (MetS) defined by the National Cholesterol Education Program (NCEP) 2004 and NCEP 2001 criteria. In an attempt to address this discrepancy, they have raised several interesting questions. The first is whether this association was present only in RA patients treated with MTX monotherapy or also in the subgroup treated with MTX as part of combination therapy. The results presented in our original paper were based on analysing all patients receiving MTX $(n=214)$, irrespectively of whether this was monotherapy or combination therapy; however, adjustment was made in our multivariate model for other antirheumatic medications. In addition to this, in the subgroup of patients taking MTX monotherapy $(n=116)$ (Table 1$)$, we have now replicated our original findings, thus again supporting the possibility of a drugspecific effect. Second, Raterman and colleagues request further clarification of factors found to be independent predictors of the MetS in our regression analyses. As stated in this [1] and previous [2] papers on this cohort, factors found to be independent predictors of the MetS in our population were older age $(\beta=0.034, P<0.001)$, higher health assessment questionnaire score $(\beta=0.335$, $P=0.024$ ), and less MTX use $\beta=0.663, P=0.001$ ). Diabetes and body mass index were also independent predictors of the MetS but since they are included in the MetS criteria, they were not included in the multivariate model
Table 1

Odds ratios for having the metabolic syndrome in patients receiving methotrexate monotherapy compared with those not on methotrexate

\begin{tabular}{lcc}
\hline & NCEP 2004 & NCEP 2001 \\
& OR (95\% Cl) & OR $(95 \% \mathrm{Cl})$ \\
& $\mathrm{n}=62$ & $\mathrm{n}=62$ \\
\hline Crude & $0.415(0.21-0.82)$, & $0.368(0.19-0.73)$, \\
& $P=0.011$ & $P=0.004$ \\
Model a & $0.421(0.21-0.84)$, & $0.373(0.19-0.75)$, \\
& $P=0.014$ & $P=0.006$ \\
Model b & $0.468(0.23-0.99)$, & $0.408(0.19-0.84)$, \\
& $P=0.038$ & $P=0.015$
\end{tabular}

Crude: Unadjusted model. Model a: adjusted for age and gender. Model b: adjusted for age, gender, disease duration, erythrocyte sedimentation rate, and health assessment questionnaire score. $\mathrm{Cl}$, confidence interval; NCEP, National Cholesterol Education Program; $\mathrm{OR}$, odds ratio.

(for reasons of co-linearity). Although hypothyroidism is clearly an important cardiometabolic risk factor, only 3/387 of our patients were hypothyroid and this was not an independent predictor of the MetS.

In summary, despite further investigation, we continue to demonstrate a strong association between MTX and reduced prevalence of the MetS. We remain unable to account for the conflicting findings reported by Raterman and colleagues, particularly as the descriptive characteristics of their population are similar to ours. Clearly, both studies are limited by their cross-sectional designs: the only way of establishing the 'true' effect of MTX on the MetS would be in a large prospective longitudinal study. 


\section{Competing interests}

The authors declare that they have no competing interests.

\section{Acknowledgements}

This work is supported by an Arthritis Research Campaign Clinical Fellowship grant (grant number 18848 to TET) and an Arthritis Research Campaign infrastructure support grant (grant number 17682, given to the Dudley Group of Hospitals NHS Foundation Trust, Department of Rheumatology). $\mathrm{HJ}$ is supported by an Arthritis Research Campaign Educational Research Fellowship Grant (grant number 17883). VFP is supported by a PhD scholarship from the Empirikion Institute, Athens, Greece.

\section{References}

1. Toms TE, Panoulas VF, Douglas KMJ, Kitas GD: Methotrexate therapy associates with a reduced prevalence of the metabolic syndrome in rheumatoid arthritis patients over the age of 60: more than just an anti-inflammatory effect? A crosssectional study. Arthritis Res Ther 2009, 11:R110.

2. Toms TE, Panoulas VF, Douglas KM, Griffiths HR, Kitas GD: Lack of association between glucocorticoid use and presence of the metabolic syndrome in patients with rheumatoid arthritis: a cross-sectional study. Arthritis Res Ther 2008, 10:R145. 